\title{
Os saberes docentes no processo de alfabetização.
}

\section{The teachers' knowledge in the literacy process.}

\author{
Les savoirs des enseignants dans le processus \\ d'alphabétisation.
}

\author{
Susana Soares TOZETTO
}

\section{RESUMO}

O profissional da educação deve ter compreensão do conhecimento em suas múltiplas dimensões e ser capaz de construir seu pensamento e sua ação voltados às necessidades de seu cotidiano, rompendo com os muros da escola. Compreender desta forma a ação pedagógica é buscar outras formas de ensinar, que trabalhe com uma visão mais ampliada do mundo. Assim, o presente trabalho teve por finalidade refletir sobre o processo de ensino e de aprendizagem em duas classes de alfabetização, investigando os sáberes docentes dos professores alfabetizadores, em relação ao procesşo de construção da escrita pela criança. Os procedimentos utilizados foram observações e entrevistas que oportunizaram um aprofundamento acerca do pensamento do docente responsável pelo processo de alfabetização. Ao concluirmos nossa pesquisa, percebemos a importância do comprometimento do professor alfabetizador com a aprendizagem do aluno.

Palavras - chave: alfabetização, saberes docentes, aprendizagem.

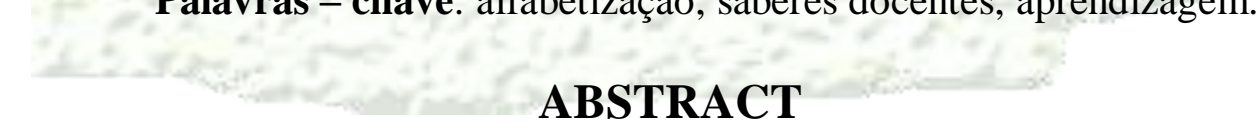

The educational professional must have the knowledge comprehension in its multiple dimensions and to be able to build his thought and his action oriented towards his daily live needs, breaking down the walls of school. Understanding this way, the pedagogical action is to seek other ways to teach, to work with a broader world vision. Thus, this work reflected about the teaching and learning process into two classes of literacy, investigating this kind of teachers' knowledge in respect of the writing construction process by child. The used procedures were observations and interviews which gave us a deeper thought about the responsible teacher of the literacy process. To conclude our research, we realize the literacy importance teacher's commitment with the student's learning. 
Index terms: literacy, knowledge teacher, learning.

\section{RÉSUMÉ}

Le professionnel de l'éducation doit avoir compréhension de la connaissance dans leurs multiples dimensions, capable de construire sa pensée et son action tournées aux nécessités de son quotidien, en rompre avec les parois de l'école. La compréhension de cette forme de l'action pédagogique, c'est chercher d'autres formes d'enseigner qui travaillent avec une vision plus élargie du monde. Ainsi, le présent travail a eu la finalité de refléchir sur le processus d'enseignement et d'apprentissage dans deux classes d'alphabétisation, en enquêtant les savoirs des enseignants d'alphabétisation, concernant le processus de construction de l'écriture par l'enfant. Les procédures utilisées ont été des commentaires et des entrevues qui ont donné un approfondissement dans la pensée du professeur responsable du processus d'alphabétisation. Dans la conclusion de notre recherche, nous percevons l'importance de l'engajement de l'enseignant à l'apprentissage de l'élève.

Mots clés: alphabetization, saviors de l'enseignant, apprentissage.

\section{Introdução}

No mundo moderno, a ciência substitui a religião como autoridadé intelectual e, culturalmente, se estabelece uma nova visão de mundo. Organizam-se as diversas instituições balizadas no conhecimento científico e a escolā se afirma nesse contexto. O espaço escolar sistemátiza e transmite informações, sendo responsável pela socialização objetiva das mesmas no contexto atual. Essa instituição foi criada para transmitir conhecimentos científicos mediante as exigências do processo social em construção, mas com o desenvolvimento das forças produtivas do capital, ela passa a atender às necessidades do imediato, minimizando a reflexão profunda, abrangente $\mathrm{e}$ complexa. Nesse contexto, a escola veio para atender ao mercado de trabalho, objetivando atuar no campo prático, utilitarista.

Com a desvalorização da escola enquanto instituição responsável pelo repasse e difusão do conhecimento científico, sente-se um 
esvaziamento teórico na formação de cidadão, que fica fragilizada. Essa organização não está acompanhando as exigências da contemporaneidade, ainda trata os conhecimentos e as informações de forma sequencial e hierarquizada. Entretanto, na modernidade ${ }^{1}$, ela tornou-se legitimadora do crescimento, da ascensão social: só progride quem vai à escola. Com a ascensão do conhecimento científico nos séculos XVIII e XIX, a escola afirma-se e se eleva em sua soberania.

A construção, transmissão, discussão do conhecimento são funções da instituição escolar na sociedade moderna. Portanto, o conhecimento deve ser tratado de maneira que todos possam compreender e aplicar na realidade cotidiana, melhorando sua condição de vida e ampliando seus projettos. Nesse sentido, percebemos um desafio para a escola e, para atendê-lo, esperamos professores preparados para atuar na complexidade das relações de sala de aula realizando ações concretas, voltadas para a realidade. Um sujeito que assuma "sua prática a partir dos significados que ele mesmo the dá, um sujeito que possui conhecimentos e um saber-fazer provenientes de sua própria atividade e a partir dos quais ele estrutura e a orienta" (TARDIF, 2002 , p.230). Neste tipo de prática, se faz pertinente a constante reflexão que é uma atitude esperada de todo professor quando se depara com situações de conflito e incertezas; da mesma forma, que fal profissional possa contar com uma formação calcada na racionalidade prática ${ }^{2}$, legitimada pelo conhecimento científico.

O intelectual crítico deve estar presente na modernidade para fazer leituras da realidade organizando situações de ensino em que as interações com o conhecimento proporcionem a transformação da informação do senso comum em uma abordagem científica. Para isto, o professor não poderá ficar restrito à sua área, se faz necessária uma ação docente que contemple o

\footnotetext{
${ }^{1}$ A modernidade, segundo Tarnas (2003), se configura no decorrer dos séculos XVIII e XIX, com um pensamento impessoal, regido por leis naturais e compreensíveis a partir da ciência. Assim, a ciência substituía a religião como autoridade intelectual, passando a ser definidora da visão cultural do mundo.

${ }_{2}$ Racionalidade Prática entendida como modelo reflexivo, em que o professor constrói seu conhecimento profissional de forma idiossincrática e processual (cf. MIZUKAMI, 2002).
} 
ato de educar em sua amplitude. O profissional da educação deve ter compreensão do conhecimento em suas múltiplas dimensões, ser capaz de construir seu pensamento e sua ação voltados às necessidades de seu cotidiano, rompendo com os muros da escola. Compreender desta forma a ação pedagógica é buscar outras formas de ensinar que trabalhem com uma visão mais ampliada. Entretanto, sem uma fundamentação básica, essencial, o professor não tem alcance às discussões mais profundas sobre a situação social da educação, levando-o à alienação dos problemas que enfrentamos na modernidade.

O contexto da modernidade, entre outras situações, exige sujeitos criativos, atualizados, que resolvam os problemas encontrados em seu ofício. Entretanto, percebe-se através das ações do professor na escola ${ }^{3}$ é que ele ainda não atende a essas exigências. Isso retoma a crítica contemporânea, que discute a banalização da formação do profissiónal da educação, construindo uma imagem de que qualquer sujeito é capaz de ensinar. Entender o ato de ensinar de maneira simplista, sem superar a dicotomia teoria /prática, escola/vida, não possibilita alterar as práticas de sala de aula. Desta forma, é necessário identificar o professor como sujeito do conhecimento, com consciência forjada na relação da prática com a teoria, que reconheça o seu papel histórico, bem como a possibilidade de criar e modificar sua ação docente; sendo que, a teoria deverá oferecer perspectivas de análise do contexto- no qual o docente está imerso, e a prática proporcionará experiências concretas em constante processo de reelaboração. Portanto, ao professor, não se reduz à função de transmissão dos conhecimentos, de submissão e de reprodução; existe também a problematização da realidade, pois são pertinentes ao trabalho do professor as ações produzidas na diversidade.

\footnotetext{
${ }^{3}$ Até pouco tempo, a escola tinha o monopólio da transmissão do conhecimento, sendo o professor seu principal agente transmissor. Hoje, é urgente a necessidade da reorganização da escola, pois esta não pode ficar atrelada à reprodução dos conhecimentos produzidos socialmente (UNESCO, 2004).
} 


\section{Refletindo sobre o caminho}

Em uma sociedade na qual a reflexão e o conhecimento tornaram-se os principais instrumentos e na qual a escola tem como finalidade o desenvolvimento da autonomia, a criatividade, o espírito de pesquisa, a cooperação e a solidariedade necessitam de professores com domínio de saberes e capazes de ensiná-los. O saber é uma necessidade vital ao professor, numa instância em que possa ser dominado, produzido e socializado pelos mesmos. Assim, ao mesmo tempo o professor conhece e produz conhecimentos sociais, culturais, humanos, históricos, entre outros.

Ao discutir a formação do profissional da educação nủma perspectiva problematizadora, percebe-se a necessidade da construção dos saberes docentes, numa ação conjunta e coerente da teoria com a prática social. Constata-se também a necessidade de uma formação inịial e continuada que estabeleça pontes de relação teórico/prática, não enfatizândo a prática em detrimento da teoria, ou atribuindo um peso excessivo à teoria. Dessa forma, Pimenta (2002, p.20) reforça essa idéia:

[...] conhecimento na ação é o conhecimento tácito, implícito, interiorizado, que está na ação [...]. É mobilizado-pelos profissionais no seu dia-a-dia, configurando um hábito. No entanto, esse conhecimento não é suficiente. [...], exigindo uma busca, uma análise, uma contextualização, possíveis explicações, uma compreensão de suas origens, uma problematização, um diálogo com outras perspectivas, uma apropriação de teorias sobre o problema, uma investigação, enfim.

Para a construção de uma prática pedagógica consciente, há que se considerar a necessidade da reflexão - ação - reflexão (cf. SCHON, 2000), pois, quando se tem à ação de refletir, é o momento de busca, de compreensão da situação, com o objetivo de resolver o problema em questão. O processo de reflexão é o momento em que se toma consciência dos atos, das ações e assim, busca-se ativamente e com certa autonomia 
encontrar caminhos que levem a aprendizagem significativa dos alunos. A capacidade de analisar a própria prática deveria ser uma ação constante no trabalho do professor, possibilitando idas e vindas enquanto profissional da educação. As reflexões e as elaborações deveriam emergir do cotidiano, fundamentando as ações. Com isso, a reflexão deveria ser uma alternativa constante no trabalho docente.

Entretanto, há que se superar a desgastada discussão da prática reflexiva, associada à excessiva ênfase na experiência empírica, ou seja, submeter à reflexão dos problemas da prática, mais imediatos, isso seria reduzir a prática pela prática. No fundo, é acentuar a visão instrumental e técnica do ensino, fazendo uso da reflexão. Ainda há outro aspecto implícito nessa concepção superficial de reflexão sobre a ação, que é o de elevar professores a intelectuais que investigam e pesquisam continuamente. É atribuir mais uma função ao docente na escola, que exige características que os mesmos muitas vezes não possuem. Seja como for, um professor intelectual, um pesquisador ou um professor que pensa sua prática para resolver problemas emergenciais, deve-se ressaltar a intencionalidade da ação pedagógica, bem como sua complexidade, pois o trabalho cotidiano do professor, não é fácil (cf. LIBÂNEO, 2002).

Sem dúvida, é importante ressaltar que a reflexão é um possível caminho para a construção de um profissional intelectual crítico. A reflexão na prática docente favorece a evolução contínua do educador. O professor percebe que não pode enfrentar todas as situações em sala de aula recorrendo aos conhecimentos técnicos e/ou pedagógicos, sentindo a necessidade da reflexão na ação e sobre a sua ação. Entretanto, não se faz necessário transformar o professor em um pesquisador, um cientista, mas sim que ele sinta a necessidade de refletir sobre seus atos, dentro de seu próprio contexto. Da mesma forma, que o docente perceba que ao refletir ele esta construindo uma prática pedagógica consistente, voltada para a 
solução de seus reais problemas. Nesse sentido, Monteiro (2001, p. 131) afirma:

[...] saberes não provêm das instituições de formação ou dos currículos, esses saberes não se encontram sistematizados no quadro de doutrinas ou teorias: eles são saberes práticos (e não da prática: eles não se aplicam à prática para melhor conhecêla, ele se integram a ela e são partes constituintes dela enquanto prática docente) [...] são a cultura docente em ação.

Os saberes são construídos nas relações interativas, pois ao mesmo tempo em que se ensina se aprende, cabendo ao professor adquirir conhecimento suficiente para analisar e selecionar quais os saberes que realmente contribuem para uma prática que atenda à complexidade do espaço da sala de aula. Administrar o dia-a-dia do trabalho docente é uma tarefa complexa que exige propostas consistentes, norteadas pela reflexão. Muitas vezes as atividades cotidianas como ler, escrever contar envolvem o professor de tal maneira que não se tem como destinar um tempo para a reflexão e a análise da situação, causando algumas vezes a não aprendizagem dos alunos e a frustração do docente em não ter ensinado. $\mathrm{O}$ sentimento é de incompetência, de impotência diante das dificuldades dos alunos e/ou da indisciplina da sala, da falta de interesse dos discentes.

Os saberes dos professores devem ser compreendidos "em íntima relação com o trabalho deles na escola e na sala de aula. [...] Isso significa que as relações dos professores com os saberes nunca são relações estritamente cognitivas: são relações mediadas pelo trabalho que lhes fornece princípios para enfrentar e solucionar situações cotidianas" (TARDIF, 2002, p. 17). Segundo esse ponto de vista, o professor das séries iniciais do ensino fundamental da escola pública, deve levar em conta seu cotidiano real, com todas as dificuldades e problemas. Sendo que, é no contexto reflexivo que se podem encontrar caminhos e elementos fundamentais para uma ação consistente, possibilitando assim, tomar posições concretas para reduzir os problemas. 
Na complexa tarefa de ensinar e aprender, o educador não pode deixar de analisar e avaliar constantemente suas ações. É na reflexão da própria ação, que se constrói e reconstrói suas ações. É necessário muito trabalho, pesquisa, saberes teóricos e práticos, para se tornar um intelectual crítico. Então, caberá ao docente construir seus saberes para desenvolver uma prática competente. Na concepção de Libâneo (2002, p.71):

\begin{abstract}
A apropriação teórica da realidade implica o desenvolvimento dos processos do pensar em relação aos conteúdos. Sabe-se que são consideráveis as deficiências do professorado em relação ao aprender a pensar, de modo que eles próprios necessitam dominar estratégias de pensar e de pensar sobre o próprio pensar.
\end{abstract}

Ainda se faz necessário acrescentar que o desafio que se coloca ao professor não é uma tarefa fácil de realizar, pois, cabe a ele construir seu saber, buscando uma atuação teórica prática consciente do mundo socíal em que está inserido visando realmente à transformação. Assim, é atravếs da análise e da reflexão que o professor conhece e confronta a realidade, mobiliza saberes para alterar o contexto quando necessário amplia seu conhecimento e forma-se como profissional da educação.

Este deve ter compreensão do conhecimento em suas múltiplas dimensões, capaz de construir seu pensamento e sua ação vọltados às suas necessidades, rompendo com os muros da escola. Compreender desta forma a ação pedagógica é buscar outras formas de ensinar, que trabalhe com uma visão mais ampliada. O professor tem um papel importante: a tarefa de problematizar situações possibilitando aos alunos momentos de reflexão e discussão. Ao intervir e mediar a construção de hipóteses, ampliamos a leitura de mundo do aluno durante o processo da aprendizagem, o professor oportuniza diferentes sentidos e significados para o aprendiz.

\title{
A escrita na escola
}


Sabe-se o quão importante é o espaço de sala de aula como um espaço para criar, um lugar de construir autorias, local de ricas experiências com o saber. Portanto, o contato com este ambiente tornou-se imprescindível para analisar a construção do conhecimento dos sujeitos envolvidos. A vida escolar merece ênfase, pois, ao entrar na escola e ao analisar o trabalho docente com o conhecimento sistematizado, se constrói vozes significativas capazes de mostrar o contexto real do espaço de aprendizagem.

O contato com o ambiente de sala de aula, realizado em uma escola municipal, que atende crianças de bairro, a maioria provinda de famílias com baixa renda, oportunizou uma reflexão sobre o processo de constrụção dos saberes docentes no ensino da escrita.

Tal escola funciona em dois turnos: manhã e tarde. $O$ foco de atenção voltou-se para o período da tarde em que encontramos uma turma de educação infantil, duas turmas do primeiro período do primeiro cíclo, com um número aproximadamente de trinta alunos em cada turma e três turmas do segundo período do primeiro ciclo, contando cada uma com um número de alunos que não ultrapassava 25.

A aquisição da escrita pelos sujeitos é um processo que se dá em virtude de suas possibilidades de interação dentro de diferentes instâncias, derivando daí conceitos importantes que todo aquele que trabalha com a escrita deve buscar compreender: o letramento ou o alfabetismo e a alfabetização.

Segundo Kleiman (1998, p.181), o letramento pode ser entendido como "as práticas e eventos relacionados com uso, função e impacto social da escrita." Para Soares (1998, p.18), o termo alfabetismo vem para designar “o estado ou qualidade de alfabetizado". Assim, percebemos que o conceito de letramento ou alfabetismo é amplo e complexo, podendo incluir ou não os processos de escolarização. 
Da mesma forma, a alfabetização pode ser vista de diferentes formas. $\mathrm{Na}$ concepção tradicional, alfabetização corresponde a processos de codificação e decodificação de sinais. Nela, a escrita é entendida como reprodução da linguagem oral supondo-se que para cada som emitido corresponde um sinal gráfico. Essa concepção originou práticas mecânicas para trabalhar com a escrita na escola cujo centro é o código (cf. CAGLIARI, 1998). Podemos ressaltar, dentro dessa concepção, uma metodologia fundamentada no positivismo que considera o construído na escola, não levando em conta o indivíduo enquanto ser social. A orientação que perpassa essa concepção de alfabetização é a de que devemos aguardar pelo desenvolvimento cognitivo da criança, atuando no momento adequado. Assim, a alfabetização avança em estágios, os quais deverão ser respeitados e seguidos pela professora alfabetizadora. $O$ ensino deve seguir o desenvolvimento biológico natural da criança, ficando o social como apêndice desse processo.

A concepção atual (contemplada nos Parâmetros Curriculares Nacionais- PCNs) aborda a alfabetização a partir de sua dimensão simbólica, ou seja, dos significados culturais que a escrita carrega. Assim, nessa concepção, não há sentido no ensino do código pelo código sendo que a sua implicação metodológica mais importante é a de trabalhar a escrita do jeito que ela aparece socialmente, isto é, através de seus usos sociais. A forma social de uso da escrita é o texto. Sendo assim, na concepção atual de alfabetização o texto é a unidade significativa, pois é produto de uma atividade discursiva oral ou escrita (cf. VYGOTSKY, 1991). Em vista disso, a alfabetização deve ser entendida como um processo amplo, o qual deverá envolver todos os aspectos da criança, respeitando sua história social de vida, bem como fazer uso dessa história para alfabetizar. O desenvolvimento passa a ser visto dialeticamente, de forma não linear, apresentando avanços e recuos no processo de aprendizagem. Assim, o 
desenvolvimento caminha concomitante com a aprendizagem, isto é, a criança tanto aprende quanto se desenvolve. Os processos são simultâneos.

A mudança das concepções de leitura e escrita adveio das mudanças das relações sociais de produção. Isto significa que o modelo que ensina apenas o código já não responde mais às exigências colocadas pela sociedade. O modelo tradicional não forma o bom leitor e o produtor de texto e é isso o que a sociedade está exigindo cada vez mais. O principal objetivo da alfabetização é que o alfabetizando faça uso dos conhecimentos adquiridos em situações reais e que os mesmos tenham aplicabilidade em seu cotidiano. A preocupação, portanto, é com a sociedade na qual o aluno está inserido.

A escrita sendo entendida como prática social possibilita ao indivíduo uma ligação real com o conhecimento. O professor mediador proporcionará situações em sala de aula que contribuirão para melhor integrar os alunos à sociedade, tornando-os cidadãos que exigirão seus direitos e saberão exercer seus deveres com consciência. Uma vez trabalhando dessa forma, o professor torna-se também o sujeito de suá práxis, agindo e sofrendo a ação de ensinar.

\section{A aprendizagem da escrita na escola}

Para a realização da presente pesquisa foram feitas entrevistas com duas professoras alfabetizadoras do primeiro período do primeiro ciclo, do período da tarde, as quais responderam a questões abertas sobre a alfabetização, envolvendo o trabalho das mesmas no cotidiano de sala de aula. As professoras entrevistadas já atuam a algum tempo na alfabetização, por isso foi questionado o motivo que as levava a atuar sempre com turmas direcionadas a alfabetização. A professora 1 colocou a seguinte resposta: Realizo o trabalho de alfabetização com muito entusiasmo, amo o que faço e por isso todos os anos escolho a turma de alfabetização. Sei que durante o 
ano a tarefa vai ser árdua e desafiadora, mas quando chegar o final do na, terei recompensa, verei meus alunos lendo e escrevendo, me sentirei útil e realizada.

Pensando dessa forma, a professora acredita que a alfabetização é um processo que se dá em um ano letivo, através do domínio do código escrito. Constatou-se que a maioria das crianças desse grupo já se encontrava lendo e escrevendo no início do segundo semestre. Ao direcionar as atividades de leitura e escrita, a professora sistematizava o código de maneira que os alunos problematizavam, discutiam, questionavam. A princípio parece que a concepção da professora é reduzida, entretanto, seus alunos têm o domínio da leitura e da escrita contextualizada de uma maneira ampla e diversa. Os saberes da experiência foram significativos para o sucesso da professora. Tardif $(2002$, p.21) afirma que

[...] os saberes oriundos da experiência de trabalho cotidiana parecem construir o alicerce da prática e da competênicia profissionais, pois essa experiência é, para o professor, à condição para aquisição e produção de seus próprios saberes profissionais.

Ao observar a sala de aula dessa professora e ao questioná-la sobre os materiais que ela utiliza para alfabetizar, a professora mostra que-não tem uma reeeita pronta. É através de pesquisas, montagem de materiais alternativos, elaboração de atividades e, acima de tudo, um trabalho árduo do professor para ensinar a escrita em uma classe de alfabetização, que se constrói o trabalho docente: Para a realização das atividades em sala de aula, utilizo o alfabeto móvel, onde as crianças montam palavras, fazem suas tentativas de escrita, reconhecem as letras, pensam na formação das palavras. Utilizo o livro didático, faço leituras com meus alunos, utilizo também livros da literatura infantil e também atividades variadas que atendem a necessidade que a turma apresenta no momento. 
O discurso da professora mostra que a construção de seus saberes esta subsidiada por leitura, pesquisa e persistência. O trabalho com os alunos é feito individual e coletivamente, através de jogos, brincadeiras, desenhos, discutindo-se amplamente a realidade, aproveitando-se da vivência das crianças para trabalhar com a escrita. Desse modo, possibilitase ao aluno interagir criticamente com o meio, não impondo métodos rígidos, muito menos cartilhas prontas e acabadas, faz-se uso da linguagem cotidiana da comunidade em que o aluno está inserido. Respeita-se o nível cognitivo no qual o alfabetizando se encontra, buscando-se alternativas de trabalho para avançar.

Entretanto, para organizar este trabalho em sala de aula, o docente necessita ter conhecimento técnico, prático, teórico sobre os aspectos mais amplos da educação e dos processos de ensino e de aprendizagem. A condução das aulas exige estudo, reflexão, um enfoque distanciádo do paradigma positivista, da simples transmissão dos conteúdos.

O posicionamento da professora 1 sobre as maiores dificuldades encontradas durante o ano letivo mostra o conhecimento teórico sobre $\delta$ processo de aquisição da escrita. O comentário foi o seguinte: Na maioria das vezes, as dificuldades tornam o trabalho do professor desafiador. Sinto dificuldades quando a criança se encontra no nível pré-silábico e não consegue avançar.

No comentário, a professora faz uma reflexão sobre o momento vivenciado pelo aluno durante a fase de construção do processo da escrita. A fala do professor reflete o conhecimento que ele tem sobre a teoria da psicogênese da escrita de Emília Ferreiro. Com este conhecimento, a professora tem a possibilidade de discutir os avanços e os retrocessos do aluno.

Partindo dessas premissas, o alfabetizador assume uma postura teórica e prática, com uma preocupação com o aluno real e suas reais necessidades. Percebe-se o valor que a docente dá aos permanentes conflitos 
para gerar avanços quando fala dos desafios e das dificuldades. Desta forma, fica clara a necessidade do domínio das concepções teóricas por parte do docente para solucionar os problemas. Observa-se na fala da professora sua preocupação com o desenvolvimento de um bom trabalho, ela sabe que mesmo ao encontrar dificuldades não pode perder de vista seu objetivo maior que é a construção do conhecimento do aluno.

Ainda a professora 1 faz uma reflexão sobre o conceito de alfabetização, ressaltando seus conhecimentos sobre o tema: A alfabetização é um processo de ensino e de aprendizagem da leitura e da escrita.

Analisando a fala da professora, constata-se que ela tem um conhecimento teórico sobre $\mathrm{O}$ conceito de alfabetização. Ela percebe a alfabetização como o domínio do código e que seu trabalho é intencional e interativo. Quando ela explicita como a criança constrói o processo de alfabetização tem-se a seguinte fala: A criança constrói o procésso de alfabetização da escrita através da visualização, e do conhecimento que vai adquirindo no dia- a-dia de sala de aula.

Assim, o discurso dessa professora ressalta que um dos aspectos fundamentais para a aprendizagem do aluno é a clareza que o docente pode ter do processo de aquisição da leitura e escrita, ou seja, das propostas que serão desenvolvidas em sala de aula, já que conhecimento do aluno é adquirido nesse espaço. Assim, considera-se que o sucesso na aprendizagem independe de como o professor se autodenomina (interacionista, construtivista, etc). O que realmente leva o aluno a aprendizagem é atitude consciente e comprometida do professor diante das dificuldades encontradas em sala de aula. Os saberes que compõem a ação do docente necessitam ter uma atualização constante, recorrer a uma pluralidade que atenda às necessidades do contexto, pois segundo Tardif (2002, p.36) "Pode-se definir o saber docente como um saber plural, formado pelo amálgama, mais ou menos coerente, de saberes oriundos da formação profissional e de saberes disciplinares, curriculares e experiênciais". 
A professora 2 relatou que atua como alfabetizadora há dezesseis anos e afirma que ela se angustia quando um aluno sente muitas dificuldades, não consegue avançar, e já se esgotaram com ele todas as possibilidades de que dispunha todas as atividades que sabia e não obtive o resultado esperado.

Fica claro na fala da professora o compromisso com a aprendizagem do aluno a qualquer custo, que são muitos os desafios a enfrentar, mas nada impede que o trabalho seja realizado com vistas ao sucesso. O educador, que se preocupa com o desenvolvimento de um bom trabalho, sabe que mesmo frente às suas limitações terá que dar conta da aprendizagem dos alunos.

Conforme se observa no discurso da professora, muitas vezes, o educador sente dificuldades e não consegue alcançar o objetivo, mas $g$ seu trabalho deve ser contínuo. Na educação, a formação e o preparo do profissional para superar obstáculos do cotidiano são fundamentais, pois quanto mais ciente estiver o professor de como se dá o processo de aquisição da escrita, mais produtiva será a aprendizagem do seu aluno. Percebe-se também a necessidade do envolvimento do educador com o processo de aquisição do conhecimento da criança. Quando a professera 2 foi questionada sobre o conceito de alfabetização, ela disse: Alfabetização é a codificação das letras para ler palavras e textos.

Para ela, o importante é a criança reconhecer as letras para poder ler e, consequentemente, escrever. Sabendo as 'partes' da escrita, a criança conseguirá chegar ao todo. O que mais influencia a prática dessa professora é a concepção estruturalista da língua, na qual a língua ainda é vista como um sistema abstrato, inato, estruturado e a linguagem escrita é um retrato fiel da linguagem oral. $\mathrm{O}$ alfabetizando necessita dominar toda a estrutura da língua para poder expressar-se com fluência. Por certo, diremos que seu conceito é reduzido e tradicional, entretanto, isso não interfere "diretamente" na aprendizagem da criança, pois a sua classe está organizada 
em duplas realizando as atividades de maneira interdisciplinar. Em sala de aula, a professora entrevistada relatou que utiliza os seguintes materiais: Uso os materiais mais variados possíveis, o alfabeto móvel, onde os alunos podem manusear letrinhas, faço autoditado, os alunos escrevem o nome das figuras, uso também a caixa de leitura e textos de livros infantis. Realizo a leitura compartilhada, onde fazemos a reflexão sobre a leitura do dia, e também fazemos a escrita e a leitura de listas, ex: animais, objetos, alimentos.

A fala da professora demonstra uma preocupação com a sistematização da leitura e da escrita de uma maneira descontextualizada, mas essas atividades garantem o domínio do código e aprendizagem por parte de todos os alunos. Sua preocupação primeira é que todos aprendám a ler. e a escrever. Quando a professora afirma que realiza leitura compartilhada, percebe-se no trabalho desenvolvido em sala de aula que ela utiliza-se de sondagens que servem como ponto de partida para a reflexão, possibilitando a interação e a troca de conhecimento entre as crianças. Ao observar as atividades na classe, o que se tem é uma dinâmica que vai além da preocupação com a mecanização. A preocupação primeira é com a aprendizagem da criança. Isto revela que o conhecimento que a professora tem sobre o processo de aquisição da escrita, vai muito além do que ela demonstrou em sua entrevista.

À preparação para a atividade complexa e multifacetada que é o ensino permanece um desafio. Afinal [...] trata-se de um profissional que vai atuar num mundo dominado pela mudança, incerteza e complexidade crescente, cujas situações e problemas não são solucionáveis com a simples aplicação de conhecimentos técnico-teóricos disponíveis. Essas circunstâncias exigem, por parte do professor, em geral, a tomada de decisão e a construção de soluções - processos em que deve selecionar alguns aspectos organizá-los e, a partir de uma avaliação, dar-lhes coerência e estabelecer uma direção para a sua ação (MIZUKAMI; REALI, 2004, p.120). 
As professoras 1 e 2 desenvolvem o trabalho em sala de aula utilizando-se de concepções chamadas de tradicionais que podem parecer com o entendimento da escrita como uma atividade mecânica. O discurso das professoras pode estar atrelado a uma visão da escrita desconectada da realidade. Entretanto, fica claro o envolvimento do professor com a construção do conhecimento da criança e uma preocupação constante com as dificuldades apresentadas pelos alunos. $\mathrm{O}$ professor se angustia quando não dá conta da aprendizagem do aluno, estando em constante busca para melhor ensinar seus alunos.

\section{Considerações finais}

Durante as observações em sala de aula, percebemos as professoras preocupadas, empenhadas em realizar o melhor trabalho possível. Os alunos se encontravam entusiasmados, alegres e expressavam gostar da professora. Em toda a classe não se encontrava um aluno que estivesse disperso ou desinteressado pela atividade, apesar de todas as dificuldades. O que se nơtava é que as crianças valorizavam o esforço da professora em ensinar mesmo que eles demonstrassem problemas para aprender. Os alunos não querem saber se a concepção de alfabetização da professora e interacionista, construtivista ou estruturalista; o que eles necessitam é ter domínio da escrita para poder ocupar um espaço na sociedade letrada; fazer uso da escrita em função de uma condição de vida digna.

Com o contexto analisado, conclui-se que o conhecimento das teorias da aprendizagem é fundamental para desenvolver um trabalho docente competente, ou seja, os saberes teóricos é que irão oferecer as bases da compreensão das ações no espaço de sala de aula, bem como auxiliar na hora da tomada de decisão.

A autonomia docente, a segurança nas práticas em sala de aula, o comprometimento com o trabalho pedagógico são fatores necessários para 
uma aprendizagem, além de significativa, que leve à construção do aluno/cidadão. Isto nos remete aos saberes da experiência que irão assegurar um caminho confiável e seguro na solução dos problemas encontrados no cotidiano da escola.

O processo de aquisição da escrita deve oportunizar as crianças um alfabetizar significativo sem dúvida, mas deve também ensinar a esses alunos a escrever a língua padrão. A alfabetização não acontece em um momento estanque em suas vidas, mas em um contínuo; vida e escola não se separam. Assim, o conhecimento da língua deve ser tratado dialeticamente, levando em conta que se trata de falantes da língua e não de desconhecidos frente a esse dialeto.

Não estamos negando a relação da práxis pedagógica com os atuais referenciais da educação, o que pretendemos é ressaltar alguns aspectos da ação docente que estão encobertos pelo discurso interacionista "mođerno". Em nome de uma proposta "atualizada", algumas ações em sala de aula não estão sendo consideradas pelos docentes, comprometendo a aprendizagem dos alunos. Há uma desvalorização pelo atendimento individual ao alfabetizando, considerando o seu nível de desenvolvimento cognitivo em detrimento do trabalho coletivo e o desenvolvimento grupal. Ao organizar o trabalho pedagógico não se dá um tratamento especial ao cốdigo enquanto código ressaltando o trabalho com o texto, mas sem considerar a necessidade de adquirir e compreender o código.

A alfabetização se modifica continuamente e tem acompanhando passo a passo o contexto sócio histórico vivenciado em cada período, chegando, até os dias atuais, com mudanças significativas na maneira de se conceber o ensino e a aprendizagem, valorizando não o melhor método, mas sim a compreensão de como o sujeito elabora o conhecimento.

As práticas em sala de aula têm frequentemente tentado construir uma proposta dita interacionista, mantendo o compromisso com a construção do conhecimento da criança. Os sujeitos pesquisados são 
conscientes de seus saberes e da formação do saber do aluno. Em função das novas formas de organização da produção e difusão do conhecimento, sentimos que os docentes constroem seus saberes no contexto da sala de aula, na confluência entre várias fontes provenientes da formação inicial, da formação em serviço, da sua história de vida, da sociedade em que estão inseridos e de outros atores educativos.

Os saberes docentes são complexos, ecléticos, polimórficos. Possuem fenômenos particulares à ação do professor, pois se dão num processo de formação do profissional da educação. Portanto, não são inatos e sim construídos e dominados na ação de ensinar. Os saberes docentes são construídos a partir das escolhas que se faz èm sala de aula, da experiểncia acumulada, dos conhecimentos adquiridos, das convicções e crenças que estes profissionais possuem.

\section{Referências bibliográficas}

BRASIL. Parâmetros Curriculares Nacionais: Língua Portuguesa. Brasil: MEC: Secretaria de Educação Fundamental, 1997.

CAGLIARI, L.C. Alfabetizando com o bá-bé-bi-bó-bu. São Paulo: Scipione, 1998.

KLEIMAN,-A. B. Ação e mudança na sala de aula: uma pesquisa sobre letramento e interação. In: ROJO, R.(org.). Alfabetização e letramento. Campinas: Mercado de Letras, 1989.

KLEIN, L. R. Alfabetização: quem tem medo de ensinar? São Paulo: Cortez, 1996.

LIBÂNEO, J.C. Reflexividade e formação de professores: outra oscilação do pensamento pedagógico brasileiro?. In: PIMENTA, S.G.; GHEDIN,E. (org). Professor reflexivo no Brasil: gênese e crítica de um conceito. São Paulo: Cortez, 2002.

MIZUKAMI, M. G. N. et al. Escola e aprendizagem da docência: processos de investigação e formação. São Carlos: Ed UFScar, 2002. 
; REALI, A. M. M. R.. Aprendizagem profissional da docência: saberes, contextos e prática. São Carlos: EDUFSCAR, 2004

MONTEIRO, Ana M. F. da C.. Professores: entre saberes e práticas. Educação e sociedade, n. 74, Campinas, CEDES, 2001.

PIMENTA. S. G.. Professor reflexivo: construindo uma crítica. In: PIMENTA, S. G.; GHEDIN, E. (org.). Professor reflexivo no Brasil: gênese e crítica de um conceito. São Paulo: Cortez, 2002.

ROJO, R.. Alfabetização e letramento. Campinas: Mercado das Letras, 1998.

SCHÖN, D. A.. Educando o profissional reflexivo. Porto Alegre: ArtMed, 2000.

SOARES, M. B.. Língua escrita, sociedade e cultura: relações, dimensões e

perspectivas. Revista Brasileira de Educação, set/out/nov/dez., 1995, p.511.

Letramento: um tema em três gêneros. Belo Horizonte: Autêntica, 1998.

TARDIF, M.. Saberes docentes e formação profissional. Rio de Janeiro: Vozes, 2002.

TARNAS, R.. A epopéia do pensamento ocidental. Rio de Janeiro: Bertrand Brasil, 2003.

TOZETTO, S. S.. Dificuldades de aprendizagem: um desafio no cotidiano escolar. Ponta Grossa, Pr. 1999, 163 p.. Dissertação (Mestrado em Educação)- Universidade Estadual de Ponta Grossa.

TOZETTO, S. S.. Mudanças nos saberes na perspectiva de professoras dos anos iniciais do ensino fundamental face à implantação de ações políticas educacionais no município de Ponta Grossa - PR. Araraquara, SP. 2008, 258 p.. Tese (Doutorado em Educação Escolar) - Universidade Estadual Paulista, Faculdade de Ciências e Letras, Campus de Araraquara.

VYGOTSKY, L. A formação social da mente. São Paulo: Martins Fontes, 1991. 
UNESCO. O perfil dos professores brasileiros: o que fazem, o que pensam, o que almejam. São Paulo: Editora Moderna, 2004.

\section{Autora:}

Susana Soares Tozetto

Docente do Departamento de Educação da Universidade Estadual de Ponta Grossa.

Contato: sustoz@brturbo.com.br

Texto recebido em maio de 2009.

Texto aprovado para publicação em julho de 2009.

\section{Como citar este texto:}

TOZETTO, S. S.. Os saberes docentes no processo de alfabetização. Revista Acolhendo a Alfabetização nos Países de Língua Portugúesa, Brasil, São Paulo, volume 1, no. 10, pp. 48 - 68, Mar. 2011. Disponível em: $<$ http://Www.acoalfaplp.net>. 